$\begin{array}{ll}\text { Balkanologie } & \begin{array}{l}\text { Balkanologie } \\ \text { Revue d'études pluridisciplinaires }\end{array} \\ & \text { Vol. } \mathbf{1 5} \mathrm{n}^{\circ} \mathbf{1} \mid \mathbf{2 0 2 0} \\ & \text { Mémoires performatives : faire des passés et des } \\ \text { présents }\end{array}$

Frank Georgi, L'autogestion en chantier. Les gauches
françaises et le « modèle » yougoslave (1948-1981) Nancy, Éditions de l'Arbre bleu, 2018

\title{
Pierre Robion
}

\section{OpenEdition \\ Journals}

\section{Édition électronique}

URL : https://journals.openedition.org/balkanologie/2550

DOI : 10.4000/balkanologie.2550

ISSN : 1965-0582

\section{Éditeur}

Association française d'études sur les Balkans (Afebalk)

\section{Référence électronique}

Pierre Robion, «Frank Georgi, L'autogestion en chantier. Les gauches françaises et le « modèle » yougoslave (1948-1981)», Balkanologie [En ligne], Vol. 15 n 1 | 2020, mis en ligne le 01 juin 2020, consulté le 05 août 2021. URL : http://journals.openedition.org/balkanologie/2550 ; DOI : https:// doi.org/10.4000/balkanologie.2550

\footnotetext{
Ce document a été généré automatiquement le 5 août 2021

(c) Tous droits réservés
} 


\title{
Frank Georgi, L'autogestion en chantier. Les gauches françaises et le " modèle » yougoslave (1948-1981)
}

\author{
Nancy, Éditions de l'Arbre bleu, 2018
}

\section{Pierre Robion}

\section{RÉFÉRENCE}

Georgi, Frank, 2018, L'autogestion en chantier. Les gauches françaises et le "modèle » yougoslave (1948-1981), Nancy, Éditions de l'Arbre bleu, 524 pages, ISBN 9791090129276

1 Spécialiste reconnu de l'histoire sociale et syndicale, Frank Georgi démontre que, loin d'être seulement une "utopie française », comme pourrait le laisser penser la place occupée par le concept dans les débats à gauche, la revendication autogestionnaire française s'est construite en permanence sur la recherche d'expériences étrangères. Parmi celles-ci, l'expérience yougoslave, par sa durée notamment, a constitué une référence majeure sur laquelle les observateurs français sont constamment revenus, pour la critiquer ou s'en inspirer. L'auteur inscrit sa démarche dans le courant visant à appréhender une dimension de l'histoire nationale au prisme de l'histoire transnationale. Il aborde ainsi les rapports de la gauche française avec l'autogestion yougoslave sous l'angle des transferts et se penche sur les adaptations et les réinterprétations auxquelles les contacts ont donné lieu en insistant sur les processus de médiation dont il décrit les modalités concrètes et les vecteurs matériels et humains. Retraçant la genèse du concept d'autogestion, l'auteur explique que ce terme, récent dans la langue française, a une riche généalogie qui l'enracine dans une tradition socialiste-libertaire, de Proudhon à Édouard Vaillant. Mais son emploi croissant à partir du milieu des années 1950 montre que l'expérience yougoslave a donné à la gauche française un vocable pour qualifier un «modèle » qui aura été durant deux décennies au centre des débats. La quête française de l'autogestion ne peut se comprendre sans 
tenir compte de la source d'inspiration qu'a constituée ce « chantier » ou cette " terre d'expérience ", selon les qualifications de l'époque.

2 Suivant un plan chronologique, l'ouvrage nous guide depuis la naissance d'un «titisme » français en 1948 à l'installation du concept dans les débats des principaux partis politiques français (chapitres II-III). En 1949, la rupture de la Yougoslavie de Tito avec l'URSS est consommée. Pour sortir de l'isolement entre stalinisme et capitalisme et contrer la propagande violemment hostile des partis communistes prosoviétiques, le régime yougoslave mise sur la conquête de "l'opinion démocratique mondiale", essentiellement des communistes non orthodoxes. En France, la propagande yougoslave va utiliser plusieurs relais. Dès 1949 , les récits des premiers voyages de "grands témoins " suscitent l'intérêt pour l'expérience yougoslave des gauches à la recherche d'un socialisme non stalinien. Dans cette nébuleuse, comprenant des intellectuels communistes ou compagnons de route, des chrétiens de gauche, des libertaires et des neutralistes, l'auteur réserve une place particulière à l'implication de trotskystes français dans la défense de la Yougoslavie socialiste, qui, selon lui, constitue une donnée essentielle à la compréhension du «titisme français ». Quoique divisés, les trotskystes resteront en effet très actifs, soit pour défendre l'expérience autogestionnaire yougoslave, soit pour la rejeter comme étant une mystification. Ceuxci seront d'ailleurs largement présents dans les brigades de travail qui rassemblent sur des chantiers en Yougoslavie plusieurs milliers de jeunes Français qui, au retour, témoignent de ce qu'ils ont vu. Ce moment bref (1950-1951) sera pour beaucoup la source d'un attachement durable à ce pays qui acquiert une aura de terre d'expérience socialiste originale de portée universelle que ses soutiens interprètent chacun à leur manière.

3 Au centre des questionnements, on trouve l'adaptabilité de l'expérience au contexte français d'une société industrielle avancée. L'image véhiculée, globalement positive, est celle d'une société socialiste en construction à travers des voies nouvelles, dans laquelle la gestion ouvrière constitue un «approfondissement du socialisme». Sur cette question, les grands partis qui dominent alors la gauche française se positionnent différemment. Georgi analyse ainsi la rencontre progressive entre l'intérêt de la SFIO en quête d'un ressourcement idéologique et la volonté du régime yougoslave d'élargir son soutien extérieur aux sociaux-démocrates occidentaux. Les délégations et échanges de visites se succèdent mais, malgré l'image plutôt positive que la plupart des dirigeants de la SFIO retirent de leurs contacts, la réalité yougoslave suscite des doutes et des réserves. Les efforts pour bâtir une démocratie économique sont salués, en particulier la participation des travailleurs aux responsabilités, mais l'absence de démocratie politique "à l'occidentale » constitue un handicap rédhibitoire. Pour ce qui est de l'attitude du Parti communiste français, l'auteur retrace clairement ses fluctuations, de la rupture de 1948 à la réconciliation entre Moscou et Belgrade, puis au gré de l'évolution ultérieure des relations diplomatiques, la question des rapports avec le régime yougoslave étant étroitement liée à celle, délicate, de la déstalinisation.

Le chapitre IV montre comment, après la mort de Staline et le rapprochement avec l'URSS, le schisme yougoslave cesse d'être un enjeu stratégique pour le communisme mondial et le titisme perd de son intérêt. La curiosité, en revanche, pour les formes d'autogestion s'accroît, avivée par les expériences hongroises et polonaises de conseils d'ouvriers. L'idée se répand qu'une forme de pouvoir ouvrier dans les entreprises représente, au-delà du cas yougoslave, la voie privilégiée d'un retour au socialisme 
authentique. L'idée de la participation est alors dans l'air du temps, à gauche, et audelà.

5 La Yougoslavie devient alors un carrefour intellectuel pour la nouvelle gauche et fait figure de laboratoire social. Le premier congrès des conseils ouvriers yougoslaves se tient en 1957 à Belgrade en présence de nombreuses délégations étrangères et d'observateurs. En Yougoslavie, la renaissance de la sociologie en tant que discipline universitaire produit une génération de chercheurs influencés par les analyses critiques, qui ambitionnent de bâtir les fondements théoriques du socialisme autogestionnaire. Ils se réunissent au sein du groupe informel Praxis, qui fait paraître une revue du même nom en 1964. À partir de 1963, les rencontres de Korčula réunissent régulièrement les grands noms de la gauche critique internationale. En 1964, deux ouvrages - L'entreprise socialiste en Yougoslavie de Georges Lasserre et Socialisme et autogestion d'Albert Meister - contribuent à populariser l'expérience yougoslave. Un pas supplémentaire est franchi en 1966 avec la création de la revue Autogestion qui va consacrer ses analyses à cette question pendant les vingt années de son existence. Sous une forme plus programmatique, le Parti socialiste unifié (PSU), dès sa création en 1960, met en avant la « gestion de l'économie par les travailleurs ».

6 Dans les chapitres V et VI, l'auteur analyse la genèse de l'appropriation du concept par la CFDT. Au lendemain de sa rupture avec le syndicalisme d'inspiration chrétienne, l'autogestion répond dans cette organisation au besoin de nourrir sa réflexion idéologique, d'asseoir son identité et de se démarquer de la Confédération générale du travail (CGT). Ici se situe la naissance de la première ébauche d'un projet autogestionnaire en France. Les échanges se multiplient avec les Yougoslaves. Le jugement tenu sur l'expérience est dans l'ensemble positif, surtout au sein du courant porté par Edmond Maire qui estime qu'elle est proche de résoudre le problème des rapports entre fonctions de direction et tâches d'exécution. Les débats internes révèlent cependant des réticences sur ses limites et l'absence de démocratie politique.

7 En mai 1968, le terme devient omniprésent dans les discours. Démocratisation de l'entreprise, planification démocratique, lutte contre les inégalités se lisent désormais à la lumière de la «perspective » autogestionnaire. En 1970, le 35 ème congrès de la CFDT formalise ces orientations et promeut le passage à une «société autogérée » sur la base de trois "piliers»: propriété sociale des moyens de production, planification démocratique, autogestion généralisée.

8 Le chapitre VII se penche sur la façon dont l'autogestion s'est dès lors installée à gauche comme un enjeu majeur du débat syndical, politique et intellectuel, la CFDT la plaçant désormais au cœur de son projet de société. La pénétration de l'autogestion dans la gauche française suit des chemins variés et prend des formes différentes. Alors que le PSU, en pleine refondation théorique et politique, reprend, au congrès de Toulouse, les trois «piliers» de la CFDT et que Michel Rocard déclare qu'avec l'autogestion il faut "viser la totalité des systèmes de décision", le nouveau Parti socialiste (PS) est nettement moins sensible au thème autogestionnaire, qu'il introduit pourtant dans le programme commun, essentiellement pour faire pièce au PCF. Mai 1968 a stimulé la recherche sur l'autogestion. La création de séminaires et cercles de recherche associés aux centres universitaires français (Centre national de la recherche scientifique, École pratique des hautes études, Maison des sciences de l'Homme) peut être considérée comme l'expression académique de la vitalité et de l'actualité du débat sur la question en France. 
9 À la fin des années 1970, le concept est largement répandu mais la référence s'épuise, ce dont traite le dernier chapitre. La CFDT se réclame toujours de l'autogestion, mais se recentre sur l'action au sein de l'entreprise et la négociation. Le projet utopique s'estompe au profit d'une démarche pragmatique. Le PS, en dépit d'une référence formelle, élabore un programme peu autogestionnaire. Paradoxalement, sur le plan théorique, la réflexion sur l'autogestion, au travers de la délégitimation du modèle totalitaire marxiste et révolutionnaire, a fini par réhabiliter, pour une partie de la gauche, les notions de libéralisme politique et, avec le marché, de libéralisme économique. La nouvelle constitution yougoslave de 1974, ambitionnant de dépasser le plan et le marché, inspire à la gauche française les plus grands doutes et la multiplication des mesures répressives suscite de fortes interrogations sur la démocratie politique. En bref, l'autogestion a cessé de faire rêver.

Durant la décennie suivante, qui s'ouvre avec la disparition de Tito (1980), les contacts se poursuivent mais reflètent de plus en plus les désillusions et les inquiétudes des observateurs français face à l'évolution de la Yougoslavie post-titiste. Les références à l'autogestion deviennent de pure forme.

11 Appuyé sur une documentation très riche - en particulier des archives diplomatiques françaises et yougoslaves, celles de syndicats et partis politiques, l'ouvrage aborde l'autogestion sous l'angle neuf de la réception et de l'appropriation de l'expérience yougoslave par les gauches françaises, tout en rappelant la généalogie de cette notion qui puise aux sources de la tradition anarcho-syndicaliste hexagonale. L'ouvrage vient combler une lacune dans la littérature historienne. Il a également l'intérêt de présenter de manière synthétique et dynamique un tableau de l'évolution des multiples courants de la gauche française depuis 1945, et des rapports entre eux. L'écriture fluide sert un contenu très dense, la bibliographie riche et solide constitue en outre un fond précieux pour de futures recherches dans ce domaine.

\section{INDEX}

Index géographique : France, Yougoslavie

\section{AUTEURS}

PIERRE ROBION

INALCO 